\title{
Risk of potential drug-drug interactions in the cardiac intensive care units
}

\author{
A comparative analysis between 2 tertiary care hospitals
}

Faisal Shakeel, PhD, Jamshaid A. Khan, PhD, Muhammad Aamir, PhD, Peer A. Hannan, PhD,

Sabahat Zehra, Pharm-D, Irfan Ullah, PhD.

$$
\begin{aligned}
& \text { ABSTRACT } \\
& \text { الأهداف: تحديد ومقارنة انتشار تفاعلات الأدوية الدوائية } \\
& \text { في وحدات الرعاية القلبية (DDIs) }
\end{aligned}
$$

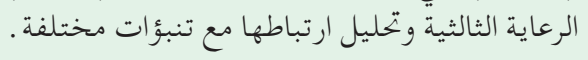

$$
\begin{aligned}
& \text { الطريقة: أجريت هذه الدراسة المستعرضة الشاملة لمدة عام }
\end{aligned}
$$

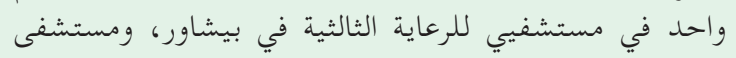

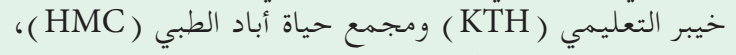

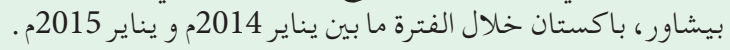

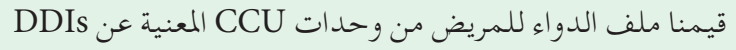

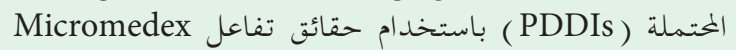

$$
\begin{aligned}
& \text { والدواء. DrugReax } \\
& \text { النتائج : كان معدل انتشار PDDIs 96.5\% و 950.7 في 95 في كلا }
\end{aligned}
$$

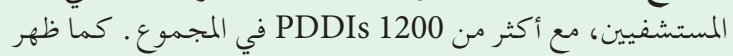

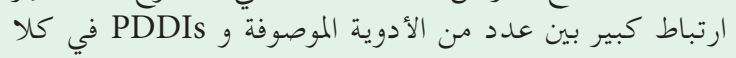

$$
\begin{aligned}
& \text { المستشفيين. }
\end{aligned}
$$

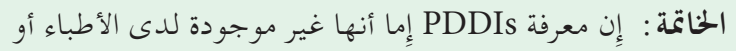

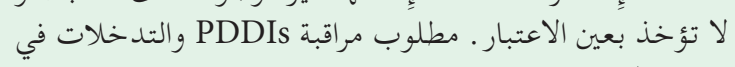

$$
\begin{aligned}
& \text { الوقت المناسب لتقليل النتائج السلبية . }
\end{aligned}
$$

Objectives: To identify and compare the prevalence of drug-drug interactions (DDIs) in the intensive cardiac care units (CCUs) of 2 tertiary care hospitals and analyze their association with various predictors.

Methods: This one-year prospective cross-sectional study was conducted in 2 tertiary care hospitals of Peshawar, Khyber Teaching Hospital (KTH) and Hayatabad Medical Complex (HMC), Peshawar, Pakistan, between January 2014 to Janury 2015. The patient medication profiles from the respective CCUs were evaluated for potential DDIs (PDDIs) using Micromedex DrugReax and Drug interaction facts.
Results: The prevalence of PDDIs was $96.5 \%$ and $95.7 \%$ in the 2 hospitals, with over 1200 PDDIs in total. A significant association was found between the number of prescribed drugs and PDDIs in both hospitals.

Conclusion: The knowledge of PDDIs is either lacking among the clinicians or is not taken into consideration. Monitoring PDDIs and timely interventions are required to minimize the adverse outcomes.

$$
\text { Saudi Med J 2018; Vol. } 39 \text { (12): 1207-1212 }
$$$$
\text { doi: 10.15537/smj.2018.12.23430 }
$$

From the Department of Pharmacy (Shakeel, Hannan, Ullah, Aamir), Sarhad University of Science and IT, and the Department of Pharmacy (Khan, Zehra), University of Peshawar, Peshawar, Pakistan.

Received 19th July 2018. Accepted 16th October 2018.

Address correspondence and reprint request to: Dr. Faisal Shakeel, Department of Pharmacy, Sarhad University of Science and IT, Peshawar,Pakistan.E-mail: faisalshakeel1@gmail.com ORCID ID: https://orcid.org/0000-0002-8468-8740

M anagement of patients in critical care units poses unique challenges due to the precarious nature of their illnesses. ${ }^{1}$ Multiple drug therapy is often used to treat these patients, which unfortunately increases the risk of unwanted medical errors exponentially. ${ }^{2}$ Drug-drug interactions (DDIs) are the one of the most easily preventable of these errors. ${ }^{3,4}$ Drug-drug interactions must be minimal, so as not to diminish the desired therapeutic effect of the drug, and prevent an increase in patient morbidity and mortality. The frequency of cardiovascular diseases has increased worldwide, and account for $30 \%$ of all deaths, of which $80 \%$ occur in developing countries. In Pakistan, 30\% of all the deaths are due to cardiovascular diseases 
and the Pakistani population has the highest risk of coronary heart disease in the world. ${ }^{6,7}$ Patients admitted to the cardiac intensive care units are especially prone to DDIs due to the large number of drugs prescribed, age and pathophysiological characteristics. ${ }^{8}$ Drug-drug interactions are one of the most significant causes of hospital admissions and re-hospitalizations.' The prevalence of potential DDIs is reportedly high in patients under treatment for cardiological conditions. The studies in Brazil have reported the prevalence of potential DDIs (PDDIs) to be $87.2 \%,{ }^{10}$ USA $27.3 \%,{ }^{11}$ and Netherlands $40.3 \%{ }^{12}$ in the cardiology departments. However, limited data are available on the prevalence of DDIs in the CCUs in Pakistan; hence, the study was designed and conducted.

Methods. This one year prospective cross-sectional study was performed at the cardiac intensive care units (CICUs) of 2 teaching hospitals in Peshawar, namely Khyber Teaching Hospital (KTH) and Hayatabad Medical Complex (HMC), Peshawar, Pakistan, between January 2014 and January 2015. Patients from the province of Khyber Pakhtunkhwa and Afghanistan visit these hospitals for treatment. The sample size was calculated to be 520 patients (260 from each hospital). Approvals from the ethical committees of both hospitals were obtained.

Inclusion criteria was set as patients admitted to the CCU for at least 24 hours and prescribed a minimum of 2 drugs. Patients who were administered medications once, or who received topical preparations and bulk sterile preparations were excluded from the study. Patient demographics and medication profile was collected on a predesigned proforma. International Conference on Harmonization guidelines for good clinical practice were followed. ${ }^{13}$

Potential DDIs were analyzed from the medication charts using both Micromedex database DrugReax and Drug Interaction Facts. These databases provide detailed information on the clinical outcome of the DDIs along with their mechanisms. Micromedex DrugReax reports the severity, documentation, onset, and mechanism of drug interacting pairs while Drug Interaction Facts additionally reports their clinical significance. The drug interacting pairs in Micromedex DrugReax are classified according to severity into 5

Disclosure. Authors have no conflict of interests, and the work was not supported or funded by any drug company. categories (contraindicated, major, moderate, minor and unknown). Onset is classified as rapid, delayed and unknown while the documentation available is classified into excellent, good, fair and unknown. The type of interactions was classified as pharmacodynamic, pharmacokinetic and unknown, while the mechanisms as synergism, antagonism, absorption, distribution, metabolism, elimination and unknown. The clinical significance is classified in Drug Interaction Facts on a level from 1 to 5 , with 1 being the most clinically significant and 5 the least. The prevalence of PDDIs can be defined as the total number of patients with at least one PDDI divided by the total number of patients.

Statistical analysis. Descriptive statistics was used and results were presented as mean $\pm S D$ and as percentages. Logistic regression was used to identify the significance of the factors associated with the presence of PDDI. The results were considered significant if $\mathrm{p}$ values were $<0.05$. The analysis was conducted using IBM SPSS Statistics for Windows, Version 20. (Armonk, NY: IBM Corp.)

Results. A total of 520 patients, 260 each from the $\mathrm{KTH}$ and HMC, were evaluated. The proportion of males was higher in both populations (male 59.23\% and female $55 \%$ ), while the mean age of the patients was $56 \pm 13.49$ years for males and $59 \pm 12.75$ years for females. Mean duration of stay in the CCU was 4 days and an average of 6 drugs were prescribed per patient in $\mathrm{KTH}$, and these respective variables were 3 and 6 drugs in HMC (Table 1). Myocardial infarction was the most common diagnosis in both hospitals (Figures 1 \& 2).

Potential drug-drug interactions. A total of 1295 PDDIs were identified in KTH, comprising of 48 drug pairs, with at least one PDDI in $96.5 \%$ of patients. At least one PDDI was present in $98.1 \%$ of the male and $94.3 \%$ of the female patients. Most of the PDDIs had moderate severity (52.6\%), good documentation (47.1\%), unknown onset $(59.1 \%)$, and were clinically significance $(58.8 \%)$. In addition, $66.9 \%$ of the PDDIs were pharmacodynamic, while $44.6 \%$ had a synergistic mechanism (Table 2). The most frequently interacting drug pair was aspirin and clopidogrel (Table 3 ).

In HMC, 1253 PDDIs were identified comprising of 93 drug pairs, with at least one PDDI in $95.7 \%$ of patients. In terms of severity, most of the PDDIs were moderate (54\%) and of good documentation (51.2\%), while the onset and clinical significance of most interactions were unknown (56.2\% and 54.7\%). Most of the interactions were pharmacodynamic (71.7\%), while synergism was the most common mechanism 
Table 1 - General characteristics of the patients admitted to the CCU.

\begin{tabular}{lrr}
\hline Variables & $\begin{array}{c}\text { KTH } \\
(\mathbf{n}=260)\end{array}$ & $\begin{array}{c}\text { HMC } \\
(\mathbf{n}=260)\end{array}$ \\
\hline $\begin{array}{l}\text { Gender (\%) } \\
\text { Male }\end{array}$ & $154(59.2)$ & $143(55.0)$ \\
Female & $106(40.8)$ & $117(45.0)$ \\
Age (years) & & \\
$\quad$ Mean \pm SD & $56 \pm 13.49$ & $59 \pm 12.75$ \\
Range & $17-100$ & $18-90$ \\
$\leq 18$ & $2(0.8)$ & $2(0.8)$ \\
$19-59$ & $137(52.7)$ & $118(45.4)$ \\
$\geq 60$ & $121(46.5)$ & $140(53.8)$ \\
Drugs prescribed per patient & & \\
$\leq 4$ & $60(23.1)$ & $34(13.1)$ \\
$5-6$ & $117(45.0)$ & $128(49.2)$ \\
$\geq 7$ & $83(31.9)$ & $98(37.7)$ \\
Stay in CCU (days) & & $145(55.7)$ \\
$\leq 2$ & $35(13.5)$ & $99(38.1)$ \\
$3-4$ & $171(65.8)$ & $16(6.2)$ \\
$\geq 5$ & $54(20.8)$ & \\
\hline \multicolumn{2}{c}{ CCU - cardiac care units } \\
\hline
\end{tabular}

Table 2 - Categories of PDDIs encountered in the CCU.

\begin{tabular}{|c|c|c|}
\hline Variable & KTH & HMC \\
\hline $\begin{array}{l}\text { Total PDDIs } \\
\text { Severity of PDDIs } \\
\text { Major } \\
\text { Moderate } \\
\text { Minor }\end{array}$ & $\begin{array}{l}\mathrm{n}=1295 \\
585(45.2) \\
681(52.6) \\
29 \quad(2.2)\end{array}$ & $\begin{array}{r}\mathrm{n}=1253 \\
72(45.7) \\
676(53.9) \\
5(0.4)\end{array}$ \\
\hline $\begin{array}{l}\text { Documentation of PDDIs } \\
\text { Excellent } \\
\text { Good } \\
\text { Fair }\end{array}$ & $\begin{array}{l}214(16.5) \\
610(47.1) \\
471(36.4)\end{array}$ & $\begin{array}{l}136(10.9) \\
641(51.1) \\
476(38.0)\end{array}$ \\
\hline $\begin{array}{l}\text { Onset of PDDIs } \\
\text { Rapid } \\
\text { Delayed } \\
\text { Unknown }\end{array}$ & $\begin{array}{r}\mathrm{n}=1295 \\
233(18.0) \\
297(22.9) \\
765(59.1)\end{array}$ & $\begin{array}{r}\mathrm{n}=1253 \\
288(23.0) \\
261(20.8) \\
704(56.2)\end{array}$ \\
\hline $\begin{array}{l}\text { Clinical significance of PD } \\
1 \\
2 \\
3 \\
4 \\
5 \\
\text { Unknown }\end{array}$ & $\begin{array}{rr}43 & (3.3) \\
266 & (20.5) \\
56 & (4.3) \\
19 & (1.5) \\
150 & (11.6) \\
761 & (58.8)\end{array}$ & $\begin{array}{r}34(2.8) \\
295(23.5) \\
56(4.5) \\
9(0.7) \\
173(13.8) \\
686(54.7)\end{array}$ \\
\hline $\begin{array}{l}\text { Type of interaction } \\
\text { Pharmacodynamic } \\
\text { Pharmacokinetic } \\
\text { Unknown }\end{array}$ & $\begin{array}{r}867(70.0) \\
415(32.0) \\
13(1.0)\end{array}$ & $\begin{array}{r}898(71.7) \\
339(27.0) \\
16 \quad(1.3)\end{array}$ \\
\hline $\begin{array}{l}\text { Mechanism of interaction } \\
\text { Synergism } \\
\text { Antagonism } \\
\text { Absorption } \\
\text { Metabolism } \\
\text { Elimination } \\
\text { Absorption/metabolism } \\
\text { Unknown }\end{array}$ & $\begin{array}{r}577(44.6) \\
291(22.5) \\
32(2.5) \\
180(13.9) \\
197(15.2) \\
5 \quad(0.3) \\
13(1.0)\end{array}$ & $\begin{array}{rr}572 & (45.6) \\
326 & (26.0) \\
2 & (0.2) \\
117 & (9.3) \\
219 & (17.5) \\
1 & (0.1) \\
16 & (1.3)\end{array}$ \\
\hline
\end{tabular}

PDDIs - potential drug-drug interactions, CCU - cardiac care units, KTH - Khyber Teaching Hospital, Peshawar, Pakistan, HMC - Hayatabad Medical Complex, Peshawar, Pakistan

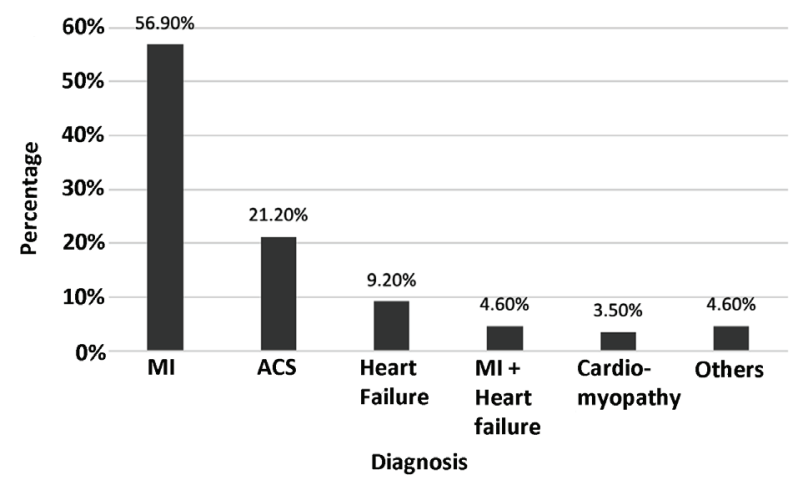

Figure 1 - Percentages of patient diagnosis in the cardiac care units of Khyber Teaching Hospital, Peshawar, Pakistan. MI - myocardial infarction, ACS - acute coronary syndrome

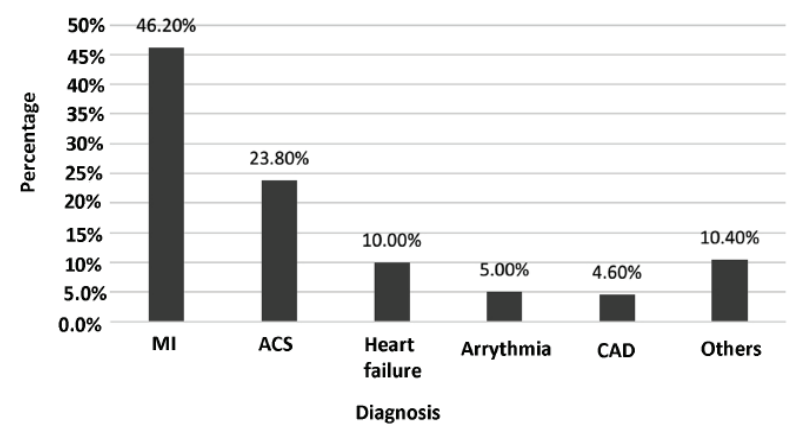

Figure 2 - Percentages of Patient Diagnosis in the cardiac care units of Hayatabad Medical Complex, Peshawar, Pakistan. MI - myocardial infarction, ACS - acute coronary syndrome, $\mathrm{CAD}$ - coronary artery disease

(45.7\%) (Table 2). The frequently occurring drug interacting pairs along with their potential outcomes (the possibility of adverse events due to the concomitant use of the drugs) are shown in Table 3.

Predictors of PDDIs. Multiple logistic regression was applied to identify the association of PDDIs with number of prescribed drugs, duration of stay and with gender. In KTH, a significant association was seen between the presence of PDDIs and prescription of 3 or more drugs $(\mathrm{OR}=35.157 ; 95 \% \mathrm{CI}=1.041-1187.61$; $p \leq 0.05)$. The association of PDDIs with duration of stay $\geq 3$ days $(\mathrm{OR}=0.916 ; 95 \% \mathrm{CI}=0.108-7.768$; $p \geq 0.05)$, and with gender $(\mathrm{OR}=0.325 ; 95 \% \mathrm{CI}=$ $0.076-1.384 ; p \geq 0.05$ ) (Table 4) were insignificant. In $\mathrm{HMC}$, there was a significant association between the presence of PDDIs and prescription of six or more drugs $(\mathrm{OR}=12.756 ; 95 \% \mathrm{CI}=2.637-61.706 ; p \leq 0.05)$. As with $\mathrm{KTH}$, an insignificant association was seen between the presence of PDDIs and duration of stay $\geq 3$ 
Table 3 - Most common interacting drug pairs in the cardiac care units.

\begin{tabular}{|c|c|c|c|}
\hline Interacting pair & $\begin{array}{l}\text { Frequency } \\
\text { KTH (\%) }\end{array}$ & $\begin{array}{l}\text { Frequency } \\
\text { HMC (\%) }\end{array}$ & Potential outcome \\
\hline Aspirin-Clopidogrel & $204(15.8)$ & $183(14.6)$ & Increased risk of bleeding \\
\hline Aspirin-Enoxaparin & $131(10.1)$ & $138(11.0)$ & Increased risk of bleeding \\
\hline Clopidogrel-Enoxaparin & $126(9.7)$ & $143(11.4)$ & Increased risk of bleeding \\
\hline Atorvastatin-Clopidogrel & $97 \quad(7.5)$ & $56(4.5)$ & Decreased formation of active metabolite of clopidogrel \\
\hline Aspirin-Nitroglycerin & $87(6.7)$ & $115 \quad(9.2)$ & $\begin{array}{l}\text { Increased nitroglycerin concentrations and depression of additive } \\
\text { platelet function }\end{array}$ \\
\hline Aspirin-Metoprolol & $84 \quad(6.4)$ & $46 \quad(3.7)$ & Decreased antihypertensive effect of metoprolol \\
\hline Aspirin-Ramipril & $84 \quad(6.4)$ & $103(8.2)$ & Decreased ramipril effectiveness \\
\hline Aspirin-Furosemide & $57 \quad(4.4)$ & $54(4.3)$ & Decreased diuretic and antihypertensive efficacy \\
\hline Clopidogrel-Esomeprazole & $40 \quad(3.1)$ & - & Reduced plasma concentrations of clopidogrel active metabolite \\
\hline Ramipril-Furosemide & $33(2.5)$ & $31 \quad(2.5)$ & Postural hypotension (first dose) \\
\hline Aspirin-bisoprolol & - & $80 \quad(6.4)$ & Decreased antihypertensive effect of bisoprolol \\
\hline
\end{tabular}

Table 4 - Logistic regression analysis.

\begin{tabular}{|c|c|c|c|c|}
\hline \multirow[t]{2}{*}{ Variable } & KTH & \multicolumn{3}{|c|}{ HMC } \\
\hline & OR $(95 \% \mathrm{CI})$ & $P$-value & OR $(95 \% \mathrm{CI})$ & $P$-value \\
\hline Prescribed drugs & & $<0.05$ & & $<0.05$ \\
\hline$<3$ & & & & \\
\hline$\geq 3$ & $35.157(1.041-1187.61)$ & & $12.756(2.637-61.706)$ & \\
\hline Duration of stay & & $>0.05$ & & $>0.05$ \\
\hline$\geq 3$ & $0.916(0.108-7.768)$ & & $1.327(0.364-4.831)$ & \\
\hline Gender & & $>0.05$ & & $>0.05$ \\
\hline Male & & & & \\
\hline Female & $0.076(0.076-1.384)$ & & $0.658(0.185-2.339)$ & \\
\hline
\end{tabular}

days $(\mathrm{OR}=1.327 ; 95 \% \mathrm{CI}=0.364-4.831 ; p \geq 0.05)$, and gender $(\mathrm{OR}=0.658 ; 95 \% \mathrm{CI}=0.185-2.339 ; p \geq 0.05)$ (Table 4).

Discussion. This study was conducted in 2 tertiary care hospitals of Peshawar, the Khyber Teaching Hospital and Hayatabad Medical Complex, and the prevalence of PDDIs in the respective CCUs was 96.5\% and $95.7 \%$. Previous studies conducted in the cardiology departments of hospitals in Pakistan reported PDDI prevalence of $91.6 \%$ and $77.5 \%$, whereas high prevalences of PDDIs was also reported from India $(74.5 \%){ }^{16}$ and Brazil (70.6\%). ${ }^{17}$ However, these studies were conducted in the cardiology wards and not in the CCUs where higher prevalence would be expected. A study conducted in the US reported a prevalence of $29 \%$ in cardiothoracic ICU and $27.3 \%$ in the CCU. The prevalence reported in the Netherlands is at least one PDDI in $40.3 \%$ patients. ${ }^{12}$ Studies suggest that anticoagulants and antiplatelets are commonly involved in PDDIs in CCUs, ${ }^{8}$ and cardiac patients are susceptible to minor alterations in drug therapy which leads to multiple problems. ${ }^{11}$ Consistent with the general predominance of heart diseases in males, most patients in our cohort were also men. ${ }^{18}$ In addition, the most prevalent cardiac disease is myocardial infarction (MI). ${ }^{19}$ Potential DDIs are considered significant if they display severity as major or moderate, and documentation as excellent or good. The majority of PDDIs in this study were with moderate severity and good documentation; thus, they were significant and must be avoided to decrease the mortality and morbidity rates. Most of the PDDIs were pharmacodynamic and synergistic, consistent with other studies. ${ }^{20}$ Polypharmacy is significantly related to the increased number of PDDIs, and a strong association was seen between the number of prescribed drugs and PDDIs in this study $(p \leq 0.01)$. Previous studies have also reported a significant association between these 2 factors. ${ }^{21}$ In contrast, the association between PDDIs with either duration of stay or number of interactions were insignificant, possibly due to the brief duration in the CCU. 
Anticoagulants, antiplatelets, and antihypertensive medications are commonly used in CCUs and are also involved in the majority of the PDDIs. However, if the potential benefits outweigh the risks, the physician may prescribe them together. Various electronic databases have been useful in the identification of DDIs along with their severity, documentation, onset, mechanism and clinical significance, based on which the clinician makes the decision to continue, discontinue or modify the drug pairs. However, simply changing or discontinuing the interacting drug pairs identified by the electronic databases without analyzing the underlying mechanisms may lead to unreliable clinical decisions, thereby complicating the patient's condition. For example, aspirin and clopidogrel were the most frequently interacting pair in this study and associated with an increased risk of bleeding; however, they may be given together in some patients to prevent thromboembolism. Therefore, the final decision should be made according to the patients' specific requirements. Unfortunately, PDDIs are not properly monitored in CCUs, and many physicians are either not aware of the potential harm of PDDIs or are too burdened to consider them. Moreover, both KTH and HMC presented statistically similar results in terms of prevalence of PDDIs and their severity, documentation, onset, type, mechanism and clinical significance, which confirms the similarities in the clinical practices in both hospitals. Therefore, we recommend using electronic databases to help clinicians make patient-specific decisions after evaluating the complete details of PDDIs. However, if financial constraints limit the use of such databases, the data provided in ours and similar studies can help optimize patient therapy.

Study limitations. This study was limited to the $\mathrm{KP}$ region in Pakistan and neighboring Afghanistan. Adverse outcomes could also not be monitored due to the study design.

In conclusion, high risk of developing PDDI in patients receiving polypharmacy and lengthier stay in the CCU settings as when compared with studies conducted in cardiology wards. Regular monitoring of PDDIs and timely interventions to minimize the adverse outcomes, and the mortality and morbidity rates is recommended.

Acknowledgment. The management, administrative, and clinical staff of all the hospitals involved in this study are acknowledged for their complete cooperation during the research.

\section{References}

1. Cooke FL, Bartram T. Guest editors' introduction: human resource management in health care and elderly care: current challenges and toward a research agenda. Human Resource Management 2015; 54: 711-735.

2. Shakeel F, Khan JA, Aamir M, Asim SM, Ullah I. A multicentered pharmacoepidemiological approach to evaluate clinically significant potential drug-drug interactions in medical intensive care settings in Pakistan. Hong Kong Journal of Emergency Medicine 2018; 25: 190-195.

3. Tesfaye ZT, Nedi T. Potential drug-drug interactions in inpatients treated at the Internal Medicine ward of Tikur Anbessa Specialized Hospital. Drug Healthc Patient Saf 2017; 9: 71-76.

4. Bethi Y, Shewade DG, Dutta TK, Gitanjali B. Prevalence and predictors of potential drug-drug interactions in patients of internal medicine wards of a tertiary care hospital in India. European Journal of Hospital Pharmacy 2017; 0: 1-6.

5. Goh I, Lai O, Chew L. Prevalence and risk of polypharmacy among elderly cancer patients receiving chemotherapy in ambulatory oncology setting. Curr Oncol Rep 2018; 20: 38.

6. Misra A, Tandon N, Ebrahim S, Sattar N, Alam D, Shrivastava $\mathrm{U}$, et al. Diabetes, cardiovascular disease, and chronic kidney disease in South Asia: current status and future directions. BMJ 2017; 357: j1420.

7. Roth GA, Johnson C, Abajobir A, Abd-Allah F, Abera SF, Abyu $\mathrm{G}$, et al. Global, regional, and national burden of cardiovascular diseases for 10 causes, 1990 to 2015. J Am Coll Cardiol 2017; 70: 1-25.

8. Sharma S, Chhetri HP, Alam K. A study of potential drug-drug interactions among hospitalized cardiac patients in a teaching hospital in Western Nepal. Indian J Pharmacol 2014; 46: 152-156.

9. Armahizer MJ, Seybert AL, Smithburger PL, Kane-Gill SL. Drug-drug interactions contributing to QT prolongation in cardiac intensive care units. J Crit Care 2013; 28: 243-249.

10. Cruciol-Souza JM, Thomson JC. Prevalence of potential drug-drug interactions and its associated factors in a Brazilian teaching hospital. J Pharm Pharm Sci 2006; 9: 427-433.

11. Smithburger PL, Kane-Gill SL, Seybert AL. Drug-drug interactions in cardiac and cardiothoracic intensive care units. Drug Safety 2010; 33: 879-888.

12. Zwart-van Rijkom JE, Uijtendaal EV, Ten Berg MJ, Van Solinge WW, Egberts AC. Frequency and nature of drugdrug interactions in a Dutch university hospital. Br J Clin Pharmacol 2009; 68: 187-193.

13. Bhuiyan P, Rege N. ICH Harmonised Tripartite Guideline: guideline for good clinical practice. Journal of Postgraduate Medicine 2001; 47: ISSN: 0972-2823.

14. Murtaza G, Khan MYG, Azhar S, Khan SA, Khan TM. Assessment of potential drug-drug interactions and its associated factors in the hospitalized cardiac patients. Saudi Pharm J 2016; 24: 220-225.

15. Ismail M, Iqbal Z, Khattak MB, Khan MI, Javaid A, Khan TM. Potential drug-drug interactions in cardiology ward of a teaching hospital. Health Med 2012; 6: 1618-1624. 
16. Ramalingam K, Rajagopal SS, Kandasamy K, Krishnan K. A prospective study on potential drug interactions among hospitalized patients in the cardiology departments in tertiary care hospitals. Indian Journal of Applied Research 2018; 8 : 65-68.

17. Carvalho REFLd, Reis AMM, Faria LMPd, Zago KSdA, Cassiani SHDB. Prevalence of drug interactions in intensive care units in Brazil. Acta Paulista de Enfermagem 2013; 26 : 150-157.

18. Fairweather D, Cooper LT, Blauwet LA. Sex and gender differences in myocarditis and dilated cardiomyopathy. Curr Probl Cardiol 2013; 38: 7-46.
19. Koch MB, Davidsen M, Andersen LV, Juel K, Jensen GB. Increasing prevalence despite decreasing incidence of ischaemic heart disease and myocardial infarction. A national register based perspective in Denmark, 1980-2009. Eur J Prev Cardiol 2015; 22: 189-195.

20. Rafieii H, Arab M, Ranjbar H, Arab N, Sepehri G, Amiri M. The prevalence of potential drug interactions in Intensive Care Units. Journal of Critical Care Nursing 2012; 4: 191-196.

21. Guthrie B, Makubate B, Hernandez-Santiago V, Dreischulte $\mathrm{T}$. The rising tide of polypharmacy and drug-drug interactions: population database analysis 1995-2010. BMC Med 2015; 13 : 74. 